\title{
Relational style: Craft as social identity in Australian fashion
}

\author{
Jess Berry
}

\begin{abstract}
Hierarchical schemas that devalue craft in relation to art and design practices are less prevalent within fashion discourse, as exquisite hand-craftsmanship continues to be inextricably linked to high fashion. This paper contends that the reciprocity between art, design and craft that occurs in fashion can be better understood if one considers examples outside the confines of Parisian couture. In particular, this paper focuses on the context of Australian dress, where the presence of visibly crafted elements is often associated with artistic mechanisms of critique.
\end{abstract}

The paper surveys examples of historic and current practice to argue that 'craft' has become a 'style' associated with art, and that this style can be seen as 'relational' in that it creates a social space of recognition. I will use the examples of Jenny Kee and Linda Jackson from the 1970s and 1980s and contemporary label Romance Was Born to establish the presence of 'visible craft' as a style within Australian fashion. Comparing these practices, I argue that, in Australian fashion, visible craft is an aesthetic form that produces shared social identities of humour, kitsch and larrikinism.

\section{Introduction}

While in the wider cultural field, hierarchies of distinction have historically undervalued craft $^{1}$ within fashion discourse, handmade elements remain the hallmark of haute couture, ${ }^{2}$ differentiating it from ready-to-wear and mass-produced products. Fashion theorist Ulrich Lehmann (2005, p. 485) suggests that disciplinary distinctions between art, craft and design arose in the nineteenth century when the schema for assessing the merits of artistic production were reconsidered in light of industrial manufacturing processes. Technical proficiency was no longer the hallmark of artistic creation, and the imperative for conceptual originality increasingly distinguished hierarchies in the arts. Lehmann argues that this is significant since, at the same time that art, design and craft diverged, the fashion industry separated haute couture and ready-to-wear. This separation posited the superiority of the haute-couture

\footnotetext{
1 Art historian Glenn Adamson defines the demarcations that have historically undervalued 'craft', where art is positioned as an autonomous field of practice able to critique institutional and cultural bases, design is recognised as a discipline directed toward aesthetic functionality for the purposes of commercial or industrial outcomes and craft is projected as the critically deficient mastery of technical materials and processes (2007, pp. 10-15).

2 The term haute couture is attributed to members of the Chambre Syndicale de la Haute Couture. Members must comply with the Chambre criteria, which stipulate that patterns must be exclusively created by the fashion designer or the designer's team of permanent modellists and be made at the firm's atelier in Paris. These workshops are to employ a minimum of 15 staff. The collections are to be presented twice a year. The patterns can only be made to fit the measurements of the client and must be fitted three to five times (Jacobs, 1995).
} 
garment, because of artistic originality and uniqueness, when compared to ready-to-wear fashion, which had a commercial purpose and was massproduced. Art historian Nancy Troy (2003, p. 191) describes this relationship, stating that, 'French couturiers attempted to negotiate these conflicting ... [yet] increasingly conflated-constructs by deploying the discourses of high art and individual style to position themselves simultaneously on both sides of the divide'.

Significantly, while twentieth-century avant-garde art focused less on craftsmanship and more on conceptual concerns, high fashion continued to emphasise handcrafted attributes. In many instances, the handmade and crafted elements of haute couture and high fashion were inextricably linked to artistic imperatives. Among the numerous examples of historical and contemporary designers whose knowledge and skills of tailoring, construction and embellishment were integral to the social, political and conceptual concerns conveyed through their designs are Elsa Schiaparelli, Christóbal Balenciaga, Alexander McQueen and Martin Margiela. ${ }^{3}$

This paper contends that the reciprocity between art, design and craft apparent in the fashion field can be better understood if considered outside the confines of Parisian couture and, rather, in the context of Australian fashion. While Paris fashion still holds considerable cultural cachet, anthropologist Simona Segre Reinach argues (2011, p. 270) 'for a country or city, expressing an immediately recognisable aesthetic has become an important corollary to communicate political and economic strength' and, as such, in an age of increasing globalisation, distinctive fashion is being employed to set nations apart. Yet, how this recognisable aesthetic has been constituted in the Australian fashion context is often contradictory.

Given the harsh Australian climate, it is unsurprising that the functionality of fashion has been of primary concern to designers. Fashion historian Jennifer Craik explains: 'Australian style is considered as anything that is practical, informal and casual' (2009, p. 409). It is intriguing then, that craft has also played a significant and prominent role within Australian fashion, for the meticulous detail and precision associated with hand-craftsmanship in fashion appears to be the antithesis to the stereotypical laidback Australian lifestyle. Yet, Craik and fellow fashion historian Margaret Maynard (2001) attest to the close connection between handicrafts, Australiana motifs and fashion that has recurred throughout Australian fashion history, culminating in the iconic designs of Jenny Kee and Linda Jackson in the 1980s and more recently by the label Romance Was Born.

3 The amalgamation of craftsmanship and conceptual concerns by modernist designers is discussed by English (2007, pp. 50-57) where she argues that Schiaparelli, the 'Italian artist who made clothes', demonstrated selfreflexivity in her use of material printed with newspaper clippings about herself, and that Balenciaga, the 'Picasso of fashion', combined exquisite cut and historic references to dress worn in the paintings of Velasquez to create garments of sculptural form. Caroline Evans (2003) also identifies the relationship between craft and art in fashion with her discussion of the traditional tailoring that underpins the political concerns represented in McQueen's collections such as Highland Rape (1996) and Margiela's knowledge of construction techniques in creating garments that comply with avant-garde anti-fashion and deconstructionist tendencies. 
Referring to these historic origins, this paper will argue that craft has become a recognisable 'style' within contemporary Australian fashion. In analysing Kee's and Jackson's designs, I contend that the presence of 'visible craft' in Australian fashion has become associated with art through the mechanisms of self-reflexivity and critique. The term 'visible craft' is used to define an aesthetic of handcraft techniques that have an overt and emphasised appearance; for example, crochet, macramé and appliqué. This view will be reinforced through a case study of contemporary Australian label Romance Was Born. Similar to the flamboyantly crafted garments created by Kee and Jackson for their label Flamingo Park, Anna Plunkett and Luke Sales of Romance Was Born adopt handicraft techniques to evoke vernacular larrikinism in phantasmagorical dress. Through comparing the two labels, I will argue that the aesthetic of craft might be understood as 'relational' within Australian fashion discourse; as I will show, it functions specifically as a mode of social identity that is associated with playfulness and humour.

In understanding visible craft as a distinctive and recognisable social identity in Australian fashion, this paper draws on Nicolas Bourriaud's concept of 'relational aesthetics' coupled with Ina Blom's construction of the 'style site'. These conceptual tools offer a framework through which to consider the connections between craft, style and social identity. Following this, I offer an overview of visible craft in Australian fashion in order to establish the prevalence of this style and its ability to convey ideas about Australian culture and society, specifically focusing on Kee's and Jackson's designs. Finally, I will offer an analysis of the Romance Was Born label, which considers how the aesthetic of visible craft is continued in their contemporary designs.

\section{Relational aesthetics and reconsidered craft}

Nicolas Bourriaud's influential book Relational Aesthetics (2002) explains a particular mode of participatory art that emerged in the 1990s. The book arose from Bourriaud's curatorial practice and identifies numerous artists who are recognised for creating social situations within the gallery environment. ${ }^{4}$ Bourriaud suggests that through such social encounters, meaning is collectively created by viewer interaction rather than in private individual space and thus the audience is an essential component of the art. He argues that relational art is a disengagement from capitalist exchange, where 'The artist's practice and his behaviour as producer, determines the relationship that will be struck up with his work ... what he produces first and foremost, is relations between people and the world by way of aesthetic objects' (2002, p. 42). ${ }^{5}$ His explanation

\footnotetext{
4 Bourriaud analyses the work of numerous practitioners in relation to his thesis, including Gabriel Orozco, Rirkrit Tiravanija and Felix Gonzalez Torres, among others.

5 Bourriaud's Relational Aesthetics has been considered a highly influential characterisation of 1990s art practice; however, it is not without its critics. In particular it is worth noting Stewart Martin's (2007) argument that Bourriaud's theory of relational art fails to recognise that this type of art was not disengaged from capitalist exchange but rather fetishises social relations as a commodity.
} 
of relational art suggests a dematerialisation of the art object in favour of the activity that surrounds it. As such, relational art and aesthetics might be seen to sit within an expanded field of practice that, as Claire Bishop (2006) argues, can be associated with a variety of names, including socially engaged, participatory, interactive or collaborative art.

According to Maria Elena Buszek (2011, p. 17), current craft scholars and practitioners have adopted Bourriaud's discussion of relational aesthetics as a schema through which to interrogate the practices and purposes of craft. For example, potter Dee Taylor Graham argues that craft's functionality and its use in everyday life creates connections between people in the same way that the relational artist does, stating that 'Pots are not art. The art is in the social relationships that pots help to generate and nurture' (2009, p. 137). In applying the discourses and theories of art to reframe craft as a functional object that creates relationships within the social environment, craft engages with conceptually rigorous concerns and challenges prevailing hierarchical distinctions within the wider cultural field.

The comparison made between craft and relational art is often based in the act of physically using a craft object to create social relationships. As Paula Owen (2011, p. 86) contends, 'the act of wearing, using or participating with an art object neutralises the distance between the object and the viewer, allowing for the experience to be personal, ephemeral, associative and responsive'. Within this context, a similar argument can be made for fashion as a relational object, where the wearer's interaction with a garment provokes social response and recognition. This comparison is even more persuasive if we consider that fashion, and dress in general, have long been accounted for in the fields of anthropology and sociology as a form of social identity and interaction. As sociologist Ted Polhemus explains, appearance has always played a communicative role in society to signify group identity and create "the shared "social body" of the community' (1998, p. 74). While 'style' in the context of fashion is often associated with personal identity - rather than a mainstream trend adopted by the majority - it can also operate as collective identity (Polhemus, 1998, p. 75). Yet another proposition is possible if we consider craft as a style within fashion discourse.

Referring specifically to Bourriaud's analysis of relational aesthetics, art historian Ina Blom identifies parallels between the 'changed status of the commodity and the artwork alike', arguing that just when emotions, communications and social relations were being recognised as commodities, 'art began to be understood as a social space rather than an object' (2007, p. 15). Blom extends Bourriaud's definition of relational art and aesthetics; instead of limiting her understanding of relational aesthetics to an 'actual gathering of people engaging in various collaborative or interactive situation' (2007, p. 15), she suggests that 'style' might be considered as a social site for an interaction based in recognition and identification. 
Blom predominantly refers to style in its art-historical context, where she considers the artwork's style as a site for forming social identity. She also, however, interchangeably uses the term to refer to fashion, television, lamps and rock music, thus coalescing style with aesthetic appearance. In developing her argument, Blom draws on an essay by Andrew Benjamin that discusses Walter Benjamin's interest in the politics of fashion. She states that

The key issue here is how style is associated with the notion of appearance and how appearance in turn relates to processes of recognition and identification. The question of style then has to be thought in relation to the forms of social identity that arise from processes of recognition. (2007, p. 16)

In other words, style is reliant on the collective recognition of a particular aesthetic form, which in turn produces social identification and therefore is a 'site' of social interaction in much the same way that the relational artwork acts as a space for collective activity.

In recognising 'craft' as a 'style' within fashion it is important to understand how it symbolically functions within the fashion system. Unlike other fields of art and design that glorified what art historian Glenn Adamson describes as the 'Modernist turn towards machines and away from the hand' (2010, p. 45), in the fashion industry the handcrafted has maintained significant authority. Labour-intensive elements, such as handmade lace and embroidery, along with specialised sewing techniques, have remained a distinctive quality of haute couture and high fashion. The handcrafted in fashion signifies the hand of the artist-designer. This myth stems back to Charles Fredrick Worth's designs, which employed lavish embroidery, beading, and lace work, along with high culture and its discourses, to establish an approximation between the fashion designer and the artist in the nineteenth century. As Troy (2003) claims, Worth's success in marketing couture to bourgeois society was made possible through promotional and exhibition strategies that were closely aligned with modern art. ${ }^{6}$ Like the griffe (designer label), the handmade is a sign of authorship ${ }^{7}$ and is perceived as a symbol of authenticity and value. As historian Mary Lynn Stewart (2008) explains, labourintensive hand-sewing techniques, and their associated costs, are the underlying features that distinguish couture from decent ready-made clothes.

While the craftsmanship of haute couture is associated with art, it is also associated with luxury, where the sumptuousness of beaded embellishment, brocade and fine embroidery indicates a wearer's wealth and social status. The aesthetic of craft in haute couture and high fashion is often associated with impeccable technique that is elegant and sophisticated. In the context of Australian fashion, exquisite and understated craftsmanship can be seen in contemporary garments designed by

\footnotetext{
6 Nancy Troy outlines a number of Worth's artistic strategies in Couture Culture (2003), for example, displaying fashion in a semi-annual rhythm which was comparable to the system of Salon exhibitions at the time and marking his garments with his name, thus equating the label with the artist's signature. Troy provides further compelling comparisons between the couturier and the artist in her analysis of Jacques Doucet and Paul Poiret.

7 While the handmade elements of couture and high fashion symbolically indicate the hand of the artist/designer this work is often completed by 'back-room' workers and outsourced specialists. For example, in the 1920s, Chanel outsourced embroidery work to Russian exiles in Paris (Stewart 2008), while Valentino and numerous others employ highly skilled and specialist labourers in their ateliers.
} 
Collette Dinnigan or Akira Isogawa, among others, yet it would seem that visible craftsmanship associated with the aesthetics of amateur homemade techniques such as appliqué, crochet and cable knits have become particularly distinctive and iconic within Australian fashion discourse.

Specifically, I argue that visible craft of an exaggerated or obvious style in Australian fashion is recognised as portraying a social identity grounded in humour and playfulness. Further, this flamboyant mode of dress can be seen as a purposefully irreverent critique of high-fashion's pretentions of superior craftsmanship, and a self-reflexive method for recognising and identifying with kitsch and nostalgic aspects of Australian cultural identity. This echoes Blom's claim that style can act as a social site in the same manner as relational art. In order to firmly establish visible craft as a 'style', it is necessary to trace its presence in Australian fashion history.

\section{The presence of visible craft in Australian fashion}

The visible articulation of craft has played a significant role in Australian national culture. Craik and Maynard similarly note the prevalence of national icons and crafted surface embellishment in Australian fashion. Craik (2009, p. 435) cites the 'Australianisation of craft courses between 1890 and 1910 as a turning point when motifs of Australian flora and fauna became incorporated in decorative design', and identifies the use of Indigenous motifs in the applied arts during the 1920 s as the beginnings of this style. Likewise, Maynard traces the coupling of craft and Australiana back to the nineteenth century, when 'native plants and animals were employed as motifs for the crafts' (2001, p. 164), and examines the popularity of these forms in dress of the 1920s and 1930s. Maynard specifically cites the use of 'batik work, decorative beadwork, handpainting, appliqué and stencilling' (2001, p. 164) as popular methods for embellishing women's fashion. The techniques Maynard highlights suggest a highly visible articulation of craft as opposed to what might be considered the hidden craft elements of fashion, such as seams or pattern construction.

While the coupling of craft and Indigenous motifs became of interest again in the 1950s, the reappearance of these forms during the 1970s and 1980s was particularly iconic. At this time Australian fashion broke away from conventional approaches to dress and adopted Australiana motifs, bright colours and theatrically crafted elements that were considered 'out of line with international modes' (Maynard, 2001, p. 162). In simplifying Australian landmarks and animals as symbols of national identity, designers simultaneously created garments that appealed to tourists as souvenirs and conveyed postmodern irony in the local context. ${ }^{8}$ Maynard highlights numerous examples that display a sense of

8 Kee's knitted jumper featuring a koala on the front and a map of Australia on the back was gifted to Lady Diana Spencer in 1981 by Kim Wran, daughter of the New South Wales premier Neville Wran, as an expression of national identity. It was worn by the Princess in 1982 at a polo match and made headlines around the world regarding her modern and independent way of dressing. In the local context it was known as the 'Blinky' jumper after the children's storybook character and offered as a pattern to Australian Women's Weekly readers to make at 
playful irreverence associated with these overtly handcrafted national emblems; for instance, Jenny Banister's Australian Net mini-dress styled with 'appliquéd coloured leather boomerangs and a gumnut-and-shell fringe' (2001, p. 61).

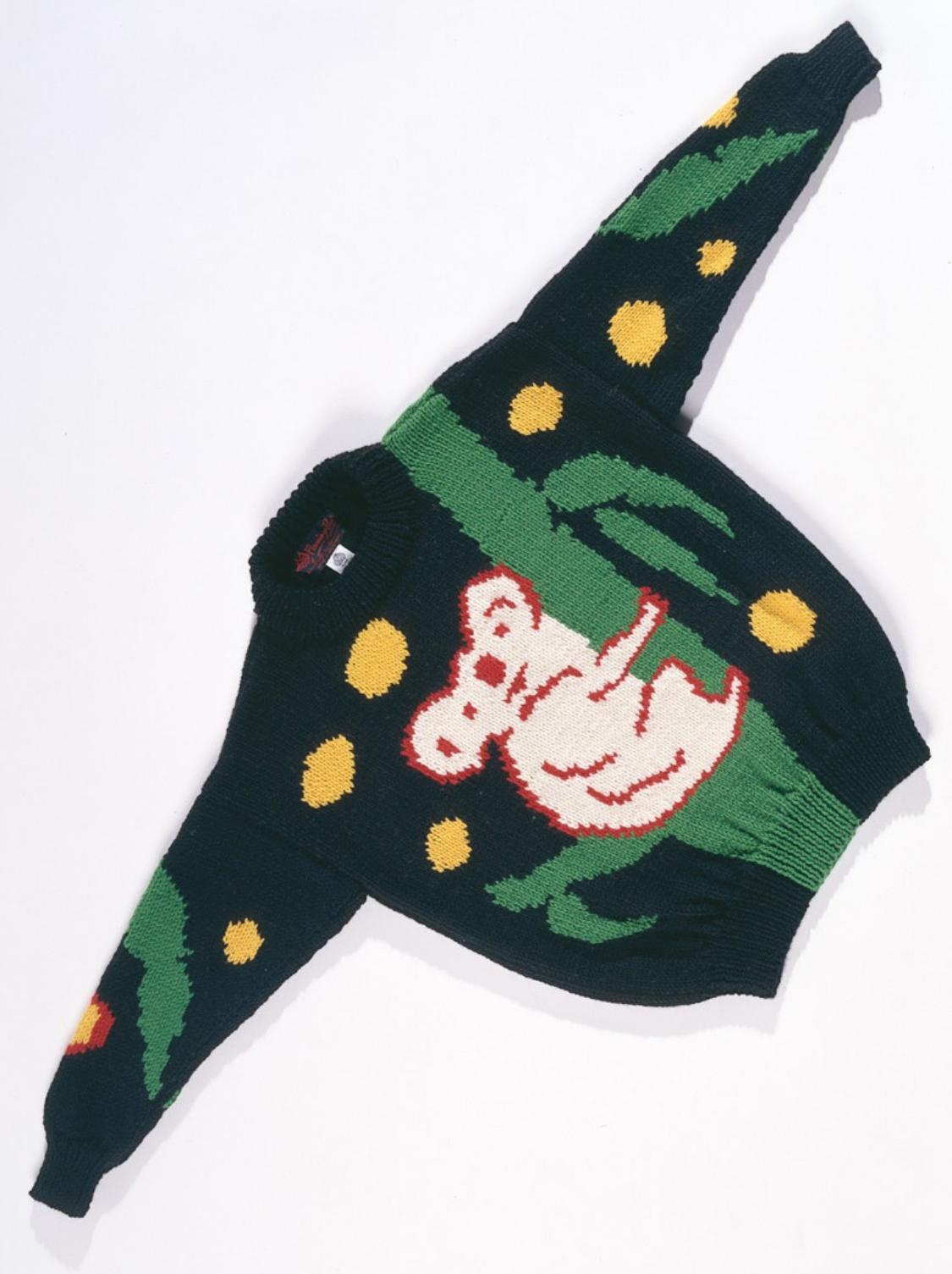

Figure 1. Blinky, 1977. Hand-knitted wool. Jenny Kee (designer), Jan Ayres (knitter), Flamingo Park, Sydney (manufacturer).

Source: National Gallery of Victoria, Melbourne. 


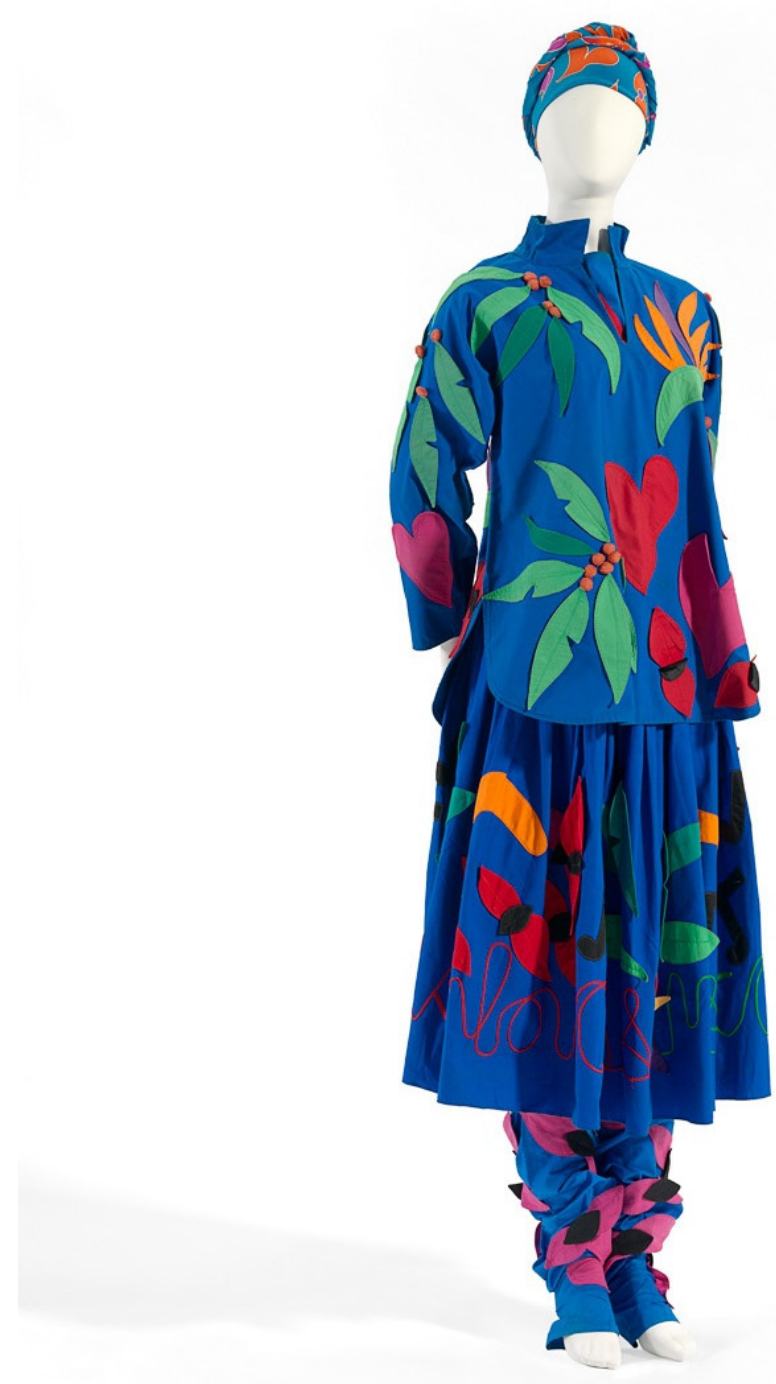

Figure 2. Wildflowers, 1976. Cotton, silk. Linda Jackson (designer).

Source: National Gallery of Victoria, Melbourne.

Kee and Jackson were at the forefront of Australian style during this period. Individually, and collaboratively as Flamingo Park, Kee and Jackson adopted a uniquely local, kitsch aesthetic that presented Australian flora and fauna as symbolic referents for knitting, macramé and appliqué decorative garments (Figures 1 and 2). Craik (2009, p. 434) specifically notes the significance of Kee's and Jackson's designs in creating a distinctively Australian dress, stating that their 'boldly coloured, extravagant designs demonstrate a new level of Australian confidence and pride'. Their designs are considered playful and ironic and often critique the pretensions of high fashion, where kitsch in the Australian context 
represents a rejection of European 'Culture' and a celebration of the ostentatious, mawkish, colloquial and quirky aspects of national identity. As curator Sally Gray argues, while Kee and Jackson both adopted motifs from multicultural reference points, in their use of typically Australian patterns they were:

Rejecting the 'cringe' and its associated insecurities, they set about restoring a sense of delight and pleasure (with some intended ironic humour) in Australian vernacular forms: indigenous flora and fauna, and popular symbols of Australian locality such as the Sydney Harbour Bridge, the Sydney Opera House and, more problematically, Aboriginal imagery. Undeterred by notions of kitsch, popular taste or high-keyed colour, they expanded the visual language of an audience tired of the received notions of what constituted good taste and haute couture. (Gray, 1999, p. 98)

While Kee's and Jackson's garments' subject matter was often derived from popular culture, their application of crafted elements was seen as a rejection of mass-production techniques, and thus classified within the realm of high fashion. When Flamingo Park was represented in Italian Vogue, and Kee's textile prints included in Karl Lagerfeld's first collection for Chanel in 1983, this perception was cemented. However, Kee's and Jackson's designs also reconsidered the type of craftsmanship that might be associated with high fashion. Instead of promoting ideals of elegant beading or intricate lacework normally associated with expensive high-end garments, Kee and Jackson elevated the aesthetics of amateur homemade craft techniques, such as cable knits and appliqué motifs. The application of these vernacular techniques implies a critique of the types of craftsmanship that high fashion and haute couture traditionally value, and thus craft acts in a mode of self-reflexive awareness associated with art. ${ }^{9}$

It is clear that Kee and Jackson were consciously aware of contextualising their work within the frame of 'high art'. They were influenced by modernist abstract painters including Sonia Delaunay, Matisse and Mondrian (English, 2010, p. 86) and collaborated with artists Bruce Goold and David McDiarmid (Jones, 2007). The status of their garments as art objects is further reinforced by exhibitions at the Art Gallery of New South Wales, Sydney, and the National Gallery of Australia in Canberra, which recognised Kee's and Jackson's designs for their avant-garde artistic merit (English, 2010, p. 81). In particular, the exhibition Australian Fashion: The Contemporary Art (1989) curated by Jane de Teliga and exhibited at the Victoria and Albert Museum in London and the Powerhouse Museum, Sydney, designated Kee's and Jackson's garments, along with the work of other 1980s Australian designers as 'art clothes'. ${ }^{10}$ De Teliga explained that she included Kee's and Jackson's garments in the exhibition because they demonstrate 'independent spirit and original concept. It is innovative

9 Adamson (2007, p. 139) makes an interesting argument regarding the perception and value of amateur craft in the context of art and the wider cultural sphere, stating that 'when craft manifests itself as an expression of amateurism, however, it becomes genuinely troublesome ... The amateur mindset implies a complete indifference to the self-critical values of the avant-garde'. He argues that where modern art has sought to define itself against art, craft has aimed to distinguish itself from amateur hobbyists. Yet, the amateur has also functioned as a form of critique within art practice; Adamson cites the work of Mike Kelly and Tracey Emin as recent examples of this. 10 Other fashion designers showcased in the exhibition included Peter Tully, Stephen Galloway and Tiwi Designs (de Teliga, 1989). 
fashion at its most exciting where art, craft and design intermingle' (1989, p. 5). Many garments in the exhibition explored Australian mythology and icons and showcased handcrafted techniques (Figure 3). As de Teliga states, 'here is the new art of contemporary life realised in dress - a fresh aesthetic combining traditional crafts with innovative design concepts' (1989, p. 7). Thus, through exhibitions held locally and internationally, Australian fashion featuring visible crafted elements became associated with art. That these garments demonstrated the conceptual applications of craft through concerns of national identity further consolidated the relationship between craft and art in Australian fashion.

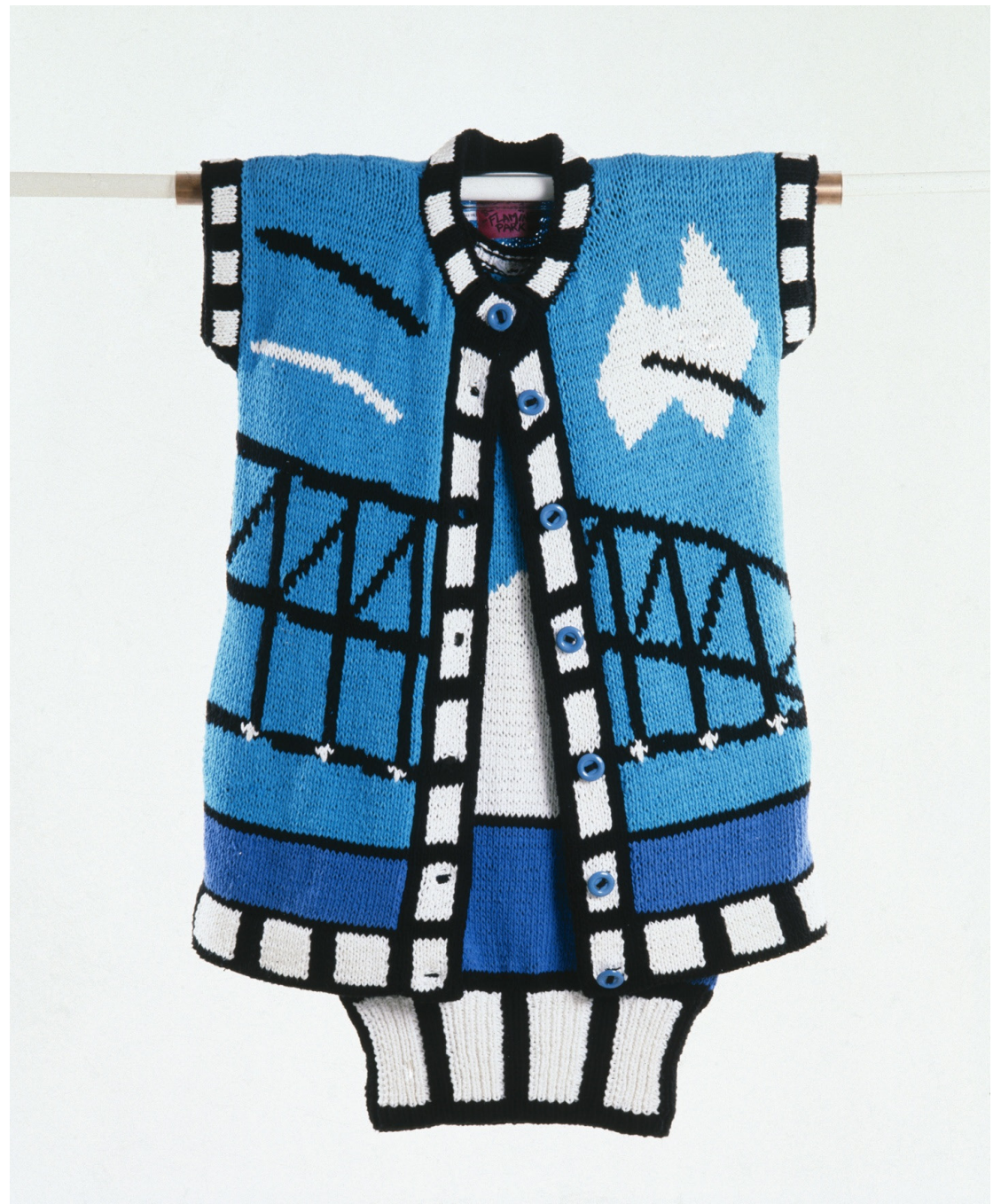

Figure 3. Women's ensemble, 1980. Jenny Kee (designer), Jane Ayres (knitter), Flamingo Park, Sydney (manufacturer). 
The subject matter and craft techniques that feature in Kee's and Jackson's garments helped establish a playful and ironic visual language of Australian dress. Their use of visible craft as a recognisable style suggested a shared social identity of larrikinism and humour that has often been associated with Australian national identity. The larrikin is a colloquial character that playfully challenges social convention and authority with humour, but also historically conveys 'loudness in dress'. ${ }^{11}$ While, as sociologist Duncan Bell suggests (2003, p. 73), 'there is no singular, irreducible, national narrative, no essentialist "national identity"', Bruce Tranter's and Jed Donoghue's sociological survey (2007, pp. 165-66) demonstrates that the larrikin continues to be a salient character of Australian national identity. Along with other 'heroic' figures, including Anzacs, convicts, postwar immigrants, sporting heroes and Aboriginal people, the larrikin is perceived to form the basis of an 'Australian Mythscape'.

Tranter and Donoghue (2007, p. 170) argue that 'national identity is constructed through, and reinforced by, everyday symbols'. While they cite movies, books and newspaper articles as reminders that reinforce aspects of national identity, it is not unreasonable to suggest that fashion can also convey these myths. As Craik (2007, p. 432) contends, the themes of Australiana are cyclical in fashion and often reflect debates of national identity or the popularity of national icons at particular points in time.

Kee's and Jackson's use of visible craft conveys a playful, larrikin social identity in its tongue-in-cheek exaggeration, application of kitsch popular imagery and refusal to conform to the dictates and pretensions of high fashion. It is clear that fashion plays a crucial role in the construction of social identity. Sociologist Fred Davis (1992, p. 16) states,

\begin{abstract}
by social identity ... I include within the concept's purview any aspect of self about which individuals can through symbolic means communicate with others, in the instance of dress through predominantly non-discursive visual, tactile, and olfactory symbols.
\end{abstract}

From this position, it is possible to conceive that specific aspects of fashion might symbolically communicate meaning and that the visible and tactile qualities of the handcrafted are able to convey social identity. Craik's (2009, p. 432) discussion of dress that incorporated crafted Australiana and Indigenous motifs argues that by 'wearing bold distinctive designs, a person dons a striking symbol of national identity and cultural difference' and suggests that this creates a dialogue between wearer and other people. Davis's and Craik's views thus reinforce the relational nature of craft in Australian dress and allude to the idea that the crafted garment acts as a social space of cultural recognition.

As I have shown, in Kee's and Jackson's designs craft communicates the narrative of larrikinism. While this association might be conveyed through their choice of motifs, it would seem that craftsmanship of an amateur or homemade

11 According to Melissa Bellanta (2009) this 'loudness in dress' was attributed to the larrikin of the 1880s who wore high-heeled boots and bell-bottom pants. 
aesthetic also plays a significant role in constructing this social identity. In this context, the handcrafted is seen to represent a critique of high fashion, which it does through the use of ironic humour, and it establishes their garments as an art form. The following section considers the contemporary label Romance Was Born, arguing that its continuation of a handcrafted aesthetic confirms that craft is a recognisable style in Australia fashion. Moreover, I argue that the visible craft in the label's work also conveys larrikinism as a social identity. This reiterates Blom's argument that style can act as a social site in the same vein as relational art.

\section{Romance Was Born: The articulation of craft in contemporary Australian fashion}

Visible craft continues to feature in contemporary Australian fashion. Designers including MaterialByProduct, Birthday Suit, and Easton Pearson have, in many ways, extended the remit of craft within Australian fashion beyond flora and fauna motifs to include a wide range of historic and cultural referents. Further, the application of craft techniques in fashion continues to be associated with art practice, with recent exhibitions at the National Gallery of Victoria, Melbourne, and the Gallery of Modern Art, Brisbane, consolidating this perception. ${ }^{12}$ Specifically, the label Romance Was Born has positioned its fashions within the frame of contemporary art through collaboration with artists such as Del Kathryn Barton and Kate Rhodes, and exhibitions at Kalliman Art Gallery, Sydney, and Karen Woodbury Gallery, Melbourne.

Romance Was Born designers Anna Plunkett and Luke Sales adopt visible craft in the form of macramé, appliqué, knitting and crochet. These handcrafted surface embellishments function as a visual cue that signifies originality, authenticity and aura for the fashion object. It would appear that craft is deliberately employed to suggest the artisan nature of their garments. In using pom-poms and macramé they evoke the handcrafted as the antithesis to the mass-produced in the same way that haute couture designers employ exquisite hand-stitched beading or embroidery to differentiate their garments from ready-to-wear apparel. As curator Prue Gibson explains (2010, p. 55), 'In direct response to the global super-brands which everyone and anyone can access and own, many designers are creating quirky, craft inspired works of art'. As such the use of visible craft has become a signature style for the label, and is associated with popular kitsch, irony and humour echoing Flamingo Park's previous designs. Like Kee and Jackson before them, Plunkett and Sale use craft to make a tongue-in-cheek critique of fashion's dictates, yet also to indicate artistic authenticity and value.

12 These recent exhibitions include Together Alone Australian and New Zealand Fashion (2010) featuring the designs of Romance Was Born and MaterialByProduct and the Easton Pearson retrospective at the Gallery of Modern Art, Brisbane (2010). 
The vernacular nature of the crafted elements Plunkett and Sales adopt suggests nostalgia for home sewing and a collective understanding of craft as a medium that can convey playfulness in Australian dress. This idea is specifically conveyed through their Spring/Summer 2006 collection entitled Regional Australia (Figure 4). In these ensembles Plunkett and Sales contravene the functional aspects of sportswear and casual attire in their exploitation of decorative embellishment. The collection primarily consists of day dresses, leggings and Dunlop Volleys (canvas tennis shoes). What makes these garments unique and unusual is the combination of contemporary artist Del Kathryn Barton's surrealist textile prints and the application of handcrafted elements in the form of crochet caps and capes. In styling the garments before a backdrop of souvenir-style Australiana tea towels, Romance Was Born relies on the sentimental associations of the handcrafted to recall nostalgia for a mythic period of naivety within Australian culture.

Romance Was Born recognises the important role of narrative and symbolic reference to avant-garde and couture fashion, realising that these considerations supply high fashion with the status of 'high culture'. Yet, the symbolic and narrative elements they choose to embellish their garments with also draw on the characteristics of craft and kitsch, namely, what sociologist Sam Binkley (2000, p. 142) identifies as a 'dependence on clichés, well-rehearsed formulas, derivative content and use of obvious, easily triggered, aesthetic responses, most typically sentimental feeling'.

The sentimentality that Plunkett and Sales draw on is closely associated with the craft techniques they adopt, where, for example, crochet, macramé and knitting, evoke symbolic reference to the domestic concerns of a bygone era. An example of this can be seen in their Spring/Summer 2009 collection Doilies and Pearls, Oysters and Shells (Figures 5 and 6). Inspired by marine life, high tea and vintage fabrics, the collection included mermaid dresses with knitted seaweed fringes, shell-encrusted garments and lced $\mathrm{VoVo}^{13}$ minis made of pom-poms. In this context, the hand-crafted elements are used ironically, exploited for their kitsch associations of 'bad art', decorativeness and debased low culture, yet are elevated to the form of high fashion. ${ }^{14}$ The relationship between craft and art is further accentuated by the artistic contributions of Esme Timbery and Patrick Doherty to the collection, which included Doherty's photographic images of elderly people knitted in metallic thread and shell encrusted shoes designed by Timbery.

13 A rectangular tea biscuit topped with pink icing, a centre strip of raspberry jam, and sprinkled with coconut. 14 Romance Was Born's status as high fashion is evidenced by the label's presence at Australia's premier fashion event Rosemount Australian Fashion Week and representation in magazines such as Vogue and Harper's Bazaar. An invitation to work as interns with John Galliano further attests to Plunketts' and Sales' reputation in the field (http://www.romancewasborn.com). 
craft + design enquiry

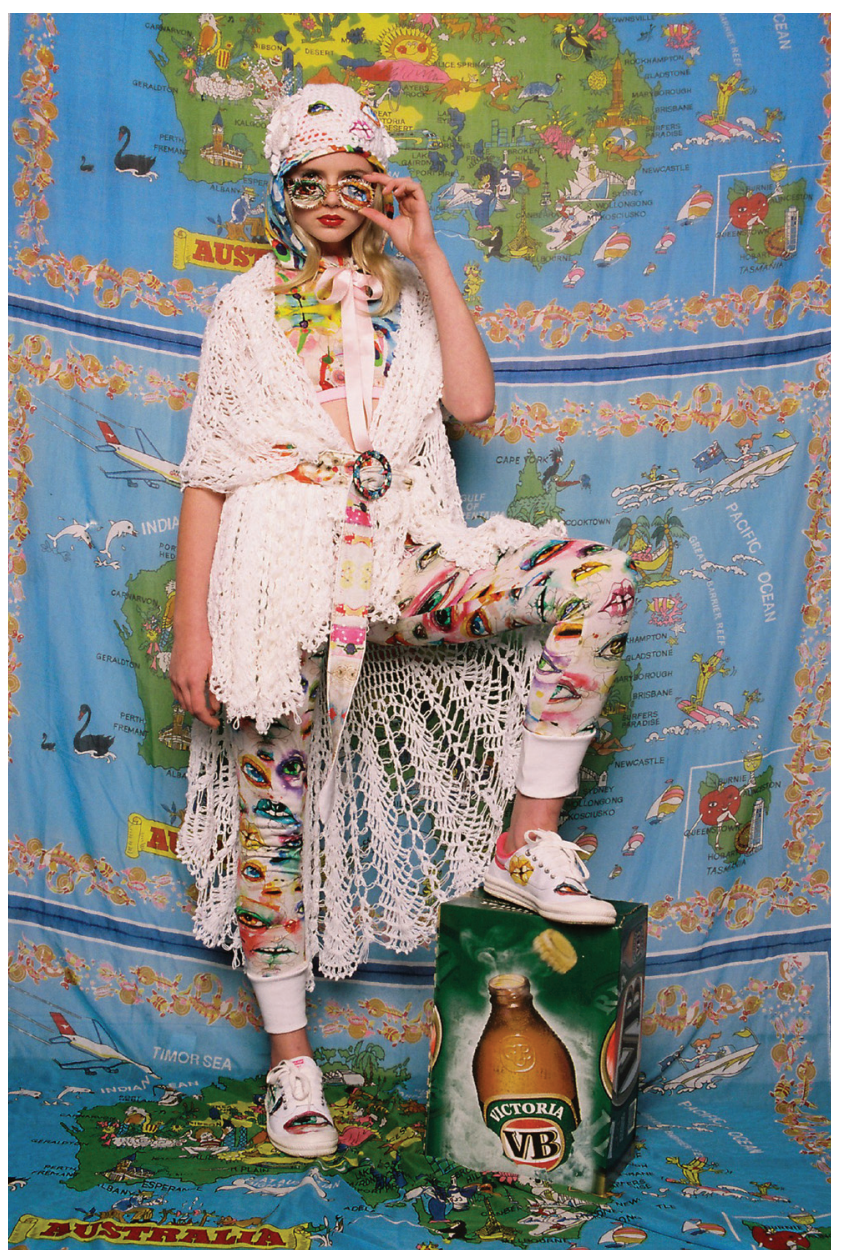

Figure 4. Romance Was Born, Regional Australia, Spring/Summer Collection 2006.

Source: Romance Was Born. http://www.romancewasborn.com 
Relational style: Craft as social identity in Australian fashion

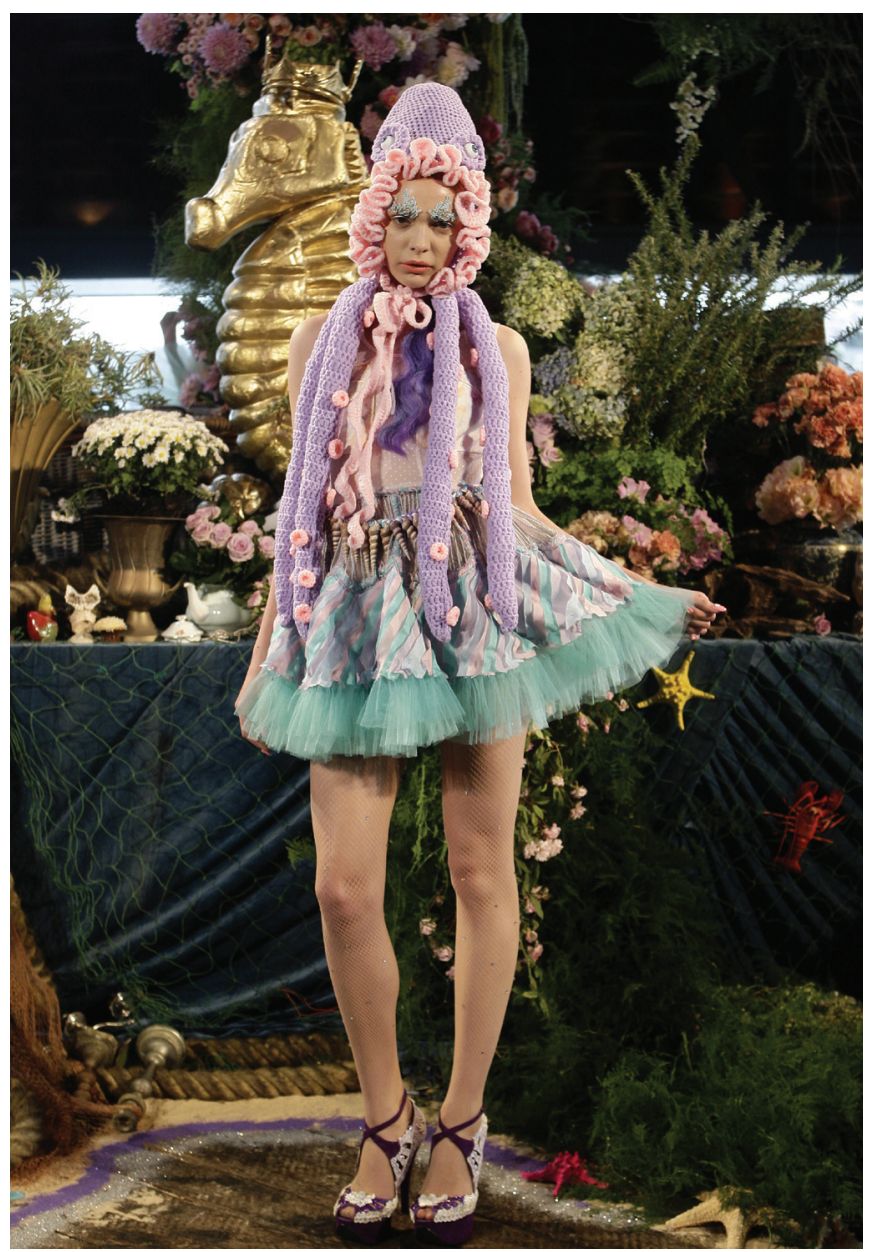

Figure 5. Romance Was Born, Doilies and Pearls, Oysters and Shells, Spring/Summer Collection 2009.

Source: Romance Was Born. http://www.romancewasborn.com 


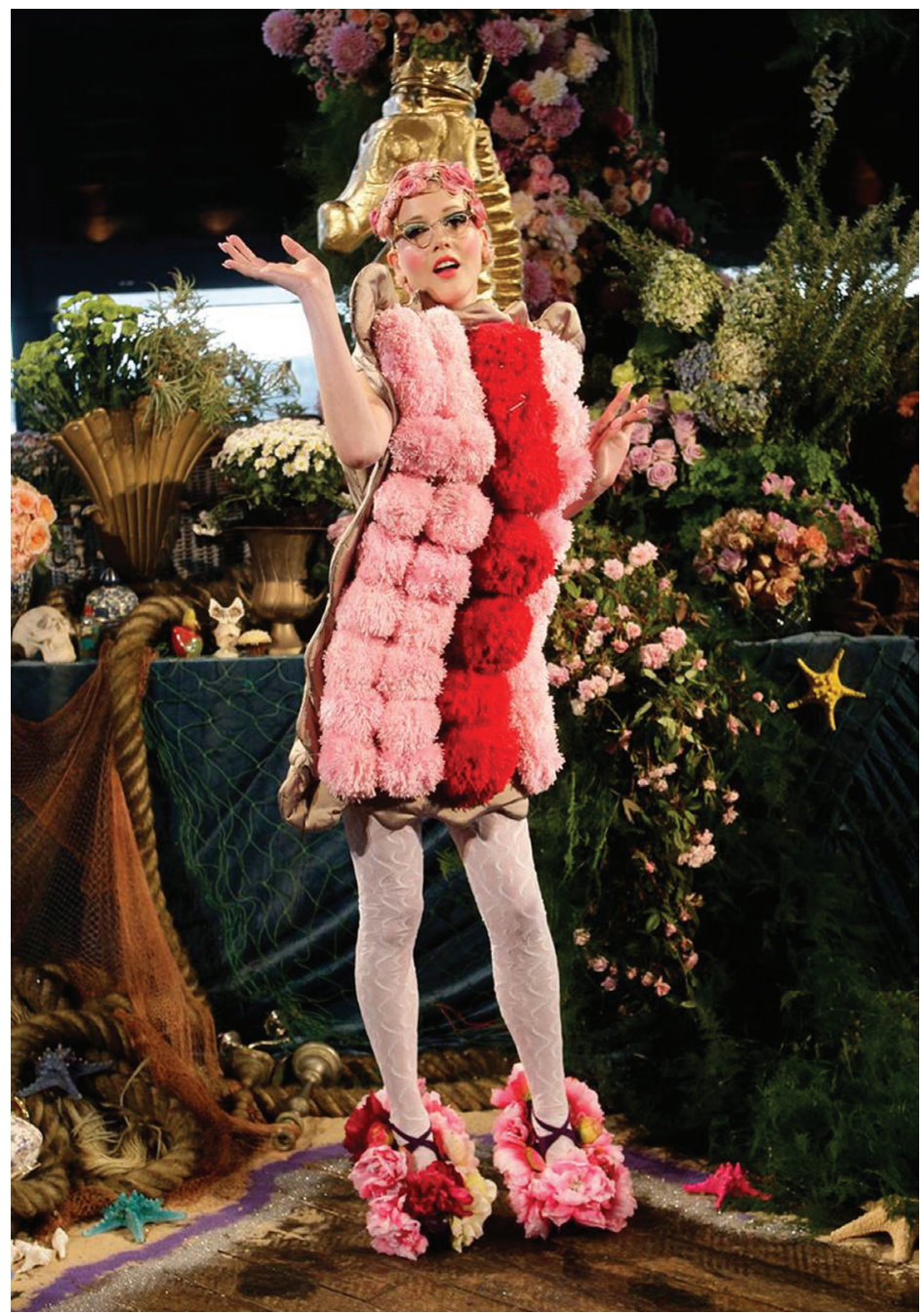

Figure 6. Romance Was Born, Doilies and Pearls, Oysters and Shells, Spring/Summer Collection 2009.

Source: Romance Was Born. http://www.romancewasborn.com

It would seem that Romance Was Born deliberately exaggerates the crafted elements of their garments as a form of self-reflexive critique. Male models adorned with crochet beards, or a pastel-coloured tutu worn with a knitted octopus bonnet appear more akin to costumes made by mothers and grandmothers for children to wear to dress-up parties than the garments of high fashion. For even the most outlandish haute couture appears to have a level of sophistication - achieved through the quality of fabric or the exquisite detail of hand embellishment - that is not immediately discernible in the Romance Was Born collections. Thus, the amateur aesthetic of visible craft in the hands of Plunkett and Sales critiques the pretensions of high fashion in a similar way to Kee and Jackson. While Plunkett and Sales have developed their designs 
beyond the native symbols that have been consistently associated with craft in Australian fashion, they continue to associate craft with ironic kitsch and so engage with the larrikin social identity associated with Australian culture.

The larrikinism and humour associated with Romance Was Born's collections are often conveyed in how its garments are styled for magazines and advertising. In Harper's Bazaar Australian Style (2009) Romance Was Born showcases visibly crafted garments, including a jacket made of deconstructed sheepskin toys and leather fringes as well as a head-dress featuring feathers and pom-poms. These garments are worn by models partaking in parochial Australian pastimes, for example sitting in the back of a ute framed by a bare-chested surfer waxing his board, or in a heavily graffitied pub toilet drinking a pot of beer. In this way, the appearance of visible craft, especially in a form that highlights its homemade or kitsch qualities, is associated with aspects of Australian culture and identity. Plunkett and Sales explain these images:

We chose different locations around Sydney that we thought represented Australian culture, which reflects the style of our lives. To us there is nothing more quintessential than beaches babes and beers. So we chose some total hotties we love, and cruised around all day long from the botanical gardens to Maroubra and then back to our home at the Cricketers Arms pub. (We don't really live there ... well, sort of). (cited in Huckbody, 2009, p. 173)

As such, Plunkett and Sales appear to be making visual comparisons between vernacular handicrafts and stereotypical 'everyday' Australian experiences. In many ways Plunkett and Sales might be seen to exaggerate the aesthetic of the handcrafted to create a style that is distinctively Australian through its appreciation of kitsch humour. In analysing examples of Romance Was Born's collections, Blom's assertion that aesthetic forms produce social identification appears relevant. While it is not possible or even desirable to identify one single aesthetic identity for Australian fashion, it would seem that the style of craft that embellishes Romance Was Born's collections is a continuation of previous narratives of humour, kitsch, and larrikinism identified by Kee and Jackson. The familiar associations of kitsch, sentimentality and nostalgia that the amateur or homemade 'style' of craft provokes becomes a site of social recognition and shared cultural identity, a site of social interaction to consider issues of Australian culture and identity.

\section{Conclusion}

Using the framework of relational art and the 'style site', this paper has argued that the articulation of visible craft is a style within Australian fashion discourse that is associated with social identity. In particular, Blom's extension of the 'relational' to consider 'style' as a site of recognition and interaction is explored with regard to the case studies of Kee and Jackson (in particular, their label, Flamingo Park) and Romance Was Born. Each of these designers considers how 
the exaggerated aesthetic of visibly handcrafted fashion, can simultaneously convey a social identity of inclusion and distinction through associations of kitsch and larrikinism.

This paper establishes that visible craft within Australian fashion is associated with 'art', because the overt handmade elements are symbolic of the artist's hand. This analogy stems from haute couture's privileging of the handmade over the massproduced, but is also related to the amateur, homemade aesthetic employed by Kee and Jackson and Plunkett and Sales. In this way, ostentatiously crafted elements can be seen as a critique of the dictates of high fashion and an avant-garde art form for its self-reflexive methods, while simultaneously complying with the values of authenticity, uniqueness and individuality that the handmade conveys. That the overt and exaggerated use of craft in Australian fashion is 'out of line with international modes' as Maynard (2001) claims, suggests that this aesthetic use of craft is a style particularly associated with a playful and laconic Australian social identity distinct from other national forms.

In this paper, I have considered how craft symbolically conveys a larrikin identity typically associated with Australian culture. While the use of Australiana motifs coupled with a homemade craft aesthetic worked in tandem to create kitsch and humorous associations in Kee's and Jackson's designs, for Plunket and Sales these same symbolic referents were achieved through the use of macramé, crochet and pom-poms and their associations with the vernacular and parochial elements of Australian culture. These examples of exaggerated, crafted dress open a dialogue between wearer and observer regarding national identity that suggests a shared social body of the community. This analysis substantiates Blom's argument that 'style' is a site for social interaction based on recognition of an aesthetic form.

Bush wear, swimwear and surf wear, and Australiana and Indigenous motifs, have been previously identified by Craik as "forms of "Australianness" [which] have dominated the sense of distinctive codes of dress that have underpinned the idea of Australian style' (2009, p. 411). In tracing the trajectory of visibly crafted elements from the 1970s and 1980s garments of Kee and Jackson to the contemporary designs of Romance Was Born, I have argued that 'craft wear' might be yet another distinctive form of Australian dress that constitutes a recognisable social identity.

Jess Berry is a Lecturer in Art Theory, Queensland College of Art, Griffith University. Her research interests include fashion history and theory, visual culture and consumerism and Australian political posters.

\section{Bibliography}

Adamson, G., 2007, Thinking Through Craft, Oxford: Berg

Adamson, G., 2010, 'Craft and the Industrial Revolution'. In: Glen Adamson ed., The Craft Reader, Oxford: Berg, pp. 43-47 
Anderson, F., 2007, 'Fashion: Style, identity and meaning'. In: Matthew Rampley ed., Exploring Visual Culture,Edinburgh University Press

Bell, D., 2003, 'Mythscapes: Memory, Mythology, and National Identity', British Journal of Sociology, vol. 54, no. 1, pp. 63-81

Bellanta, M., 2009 'Leary Kin: Australian Larrikins and the Blackface Minstrel Dandy', Journal of Social History, vol. 42, no. 3, pp. 677-95

Binkley, S., 2000, 'Kitsch as a Repetitive System: A Problem for the Theory of Taste Hierarchy', Journal of Material Culture, vol. 5, no.2, pp. 131-52

Bishop, C., 2006, 'The Social Turn: Collaboration and its Discontents', Artforum, February, 178-85

Blom, I., 2007, On the Style Site Art, Sociality and Media culture, Berlin and New York: Sternberg Press

Borriaud, N., 2002, Relational Aesthetics, France: Les Presses du reel

Buszek, M., 2011, 'Introduction: The Ordinary Made Extra/ordinary'. In: Maria Elena Buszek ed., Extra/Ordinary: Craft and Contemporary Art, Durham and London: Duke University Press, pp. 1-19

Campbell, C., 2005, 'The Craft Consumer: Culture, Craft and Consumption in a Postmodern Society', Journal of Consumer Culture, vol. 5, no. 1, pp 23-42

Craik, J., 2009, 'Is Australian Fashion and Dress Distinctively Australian', Fashion Theory, vol. 13, no. 4, pp. 409-42

Davis, F., 1992, Fashion, Culture and Identity, University of Chicago Press

De Teliga, J., 1989, Australian Fashion: The Contemporary Art, Bernard Lesser and The Museum of Applied Arts and Sciences, Sydney

English, B., 2007, A Cultural History of Fashion in the 20th Century, Oxford: Berg

English, B., 2010, 'The Art of Fashion'. In: Bonnie English and Liliana Pomazan eds., Australian Fashion Unstitched, Melbourne: Cambridge University Press, pp.81-100

Evans, C., 2003, Fashion at the Edge, New Haven and London: Yale University Press

Gibson, P., 2010, 'Clusters of Tactility, Threads of Warmth and a Return to the Senses', Sydney Design Pocketbook 31st July-15th August, Powerhouse Museum, Sydney

Gray, S., 1999, 'Celebrating Hybridity', Art \& Australia, vol. 37, no. 1, pp. 96-101 Huckbody, J. ed., 2009, Harper's Bazaar Australian Style, Sydney: Hearst/ACP Jacobs, L., 1995, The Art of Haute Couture, New York: Abbeville 
Jones, G., 2007, Jenny Kee and Linda Jackson, [online] Available at: <http://www. powerhousemuseum.com/collection/database/theme,774> [Accessed 19 March 2012]

Lehmann, U., 2005, 'Review: Couture and/or Culture', Oxford Art Journal, vol. 28 , no. 3, pp. $485-88$

Martin, S., 2007, 'Critique of Relational Aesthetics', Third Text, vol. 21, no. 4, pp. 369-86

Maynard, M., 2001, Out of Line: Australian Women and Style, Sydney: UNSW Press

Mazanti, L., 2011, 'Super-objects: Craft as an Aesthetic Position'. In: Maria Elena Buszek ed., Extra/Ordinary: Craft and Contemporary Art, Durham and London: Duke University Press, pp. 59-80

Owen, P., 2011, 'Fabrication and Encounter: When Content is a Verb'. In: Maria Elena Buszek ed., Extra/Ordinary: Craft and Contemporary Art, Durham and London: Duke University Press, pp. 83-96

Polhemus, T., 1998, 'Beyond Fashion'. In: Giannino Malossi ed., The Style Engine, Spectacle, Identity, Design and Business, New York: The Monacelli Press

Powerhouse Collection Database, n.d, 'Koala Jumper Designed by Jenny Kee, 1980', [online] Available at: <http://www.powerhousemuseum.com/ collection/database/?irn $=377626>$ [Accessed 18 April, 2012]

Reinach, S., 2011, 'National Identities and International Recognition', Fashion Theory, vol. 15, no. 2, pp. 267-72

Romance Was Born 'Profile', [online] Available at: http://www.romancewasborn. com/pdf/romance_was_born.pdf [Accessed 24 May 2011]

Stewart, M., 2008, Dressing Modern Frenchwomen: Marketing Haute Couture, 1919-1939, Baltimore: John Hopkins University Press

Tranter, B. \& J. Donoghue, 2007, 'Colonial and Post-Colonial Aspects of Australian Identity', The British Journal of Sociology, vol. 58, no. 2, pp. 165-83

Troy, N., 2003, Couture Culture, Massachusetts Institute of Technology 